\title{
The role of high-performance people management practices in Industry 4.0: The case of medium-sized Spanish firms
}

\author{
Daniel Llinas (D), Jesus Abad (D) \\ Universitat Politècnica de Catalunya (Spain) \\ daniel.llinas@iese.net,jesus.abad@upc.edu
}

Received June, 2019

Accepted December, 2019

\begin{abstract}
Purpose: This paper wants to build the case for the key role of high-performance people management practices in the development of I4.0 in SMEs. The research upon which this paper is based wants to prove that the consolidation of those practices should be a priority for any company willing to embark in this journey. The paper deals specifically with medium-sized Spanish firms which, on top, are already having significant issues with digitization.
\end{abstract}

Design/methodology: The paper starts by digging into the literature to see how past technologies have impacted productivity, followed by a review of the material available on digitization and Industry 4.0. It moves on to explore the relationship between people management practices, productivity and innovation. Finally, the focus is placed on Spanish medium-sized companies, understanding their current levels of consolidation of high-performance people management practices as well as digitization. With all this information, several propositions are posited for validation using the Delphi methodology.

Findings: I4.0 is, at its core, about productivity improvements through business process and business model innovation. People management practices are found to be strongly correlated with both productivity and innovation. It has also been found that Spanish medium-sized firms already have a significant initial gap compared to those of other OECD countries not only in productivity, but also people management practices and digitization. The experts seem to agree on the key role of people management practices and that they should be a high priority for any firm seriously thinking about industry 4.0. This is not to say that strategy or leadership will not play a paramount role in any digital transformation, but to emphasize the fact that the normally-forgotten people management practices will be important enablers in this process.

Originality/value: It is believed that this is a topic that has been mostly neglected in the I4.0 literature. In that sense, the findings of this paper could be relevant for small and medium-sized businesses embarking on the industry 4.0 journey. This will entail a significant investment of time and money and, if the key role of people management practices is not on the radar screen, it may have significant implications for the success of those ventures.

Keywords: Industry 4.0, CPPS, Productivity, Automation, Human resource management, High-performance management practices, Digitization, SMEs

Jel Codes: M10 


\section{To cite this article:}

Llinas, D., \& Abad, J. (2019). The role of high-performance people management practices in Industry 4.0:

The case of medium-sized Spanish firms. Intangible Capital, 15(3), 190-207. https://doi.org/10.3926/ic.1485

\section{Introduction}

"Cyber-physical systems" have already delivered very significant contributions to society, like the autonomous vehicle, smart electric grids or surgical robots, and more are likely to appear in the future (Monostori et al., 2016). The interaction between cyber-physical systems and production systems has produced what is known as "cyberphysical production systems" (CPPS), which are also expected to transform manufacturing. The impressive development experienced by artificial intelligence, cloud computing, 3D-printing, virtual and augmented reality, together with the constant reduction of hardware costs, will only improve their transformation potential (Kagermann, Wahslter \& Helbig, 2013). CPPS are frequently referred to as "industry 4.0" (Drath \& Horch, 2014), I4.0. Their transformation potential is the reason why CPPS are also known as the "Fourth Industrial Revolution" (Kagermann et. al, 2013; Monostori et al, 2016; Schuh, Potente, Wesch-Potente \& Hauptvogel 2013). Productivity improvements are at the core of every industrial revolution, through business process and business model innovation (Pereira \& Romero, 2017) and I4.0 is expected to be the most powerful driver of innovation over the next few decades (Ibarra, Ganzarain \& Igartua, 2018).

Literature addresses the challenges associated with I4.0 mainly from the technology, business process and business model perspectives. Even if there is some talk about talent and skills, not much attention is given to people-related issues. This paper wants to build the case for the key role of high-performance people management practices in the development of I4.0 in SMEs. The research upon which this paper is based wants to prove that the consolidation of those practices should be a priority for any company willing to embark in this journey, where special care should be taken not to be distracted by technology.

The paper deals specifically with medium-sized Spanish firms which, on top, are already having significant issues with digitization. Medium-sized companies have been selected because they are more exposed to global competition and it is believed that the impact of I4.0 may be felt more intensely by them. Nevertheless, the conclusions reached canal so be extended to the small-sized companies. It will be shown that they already have, in general, a gap in people management practices as well as in digitization, when compared to those of other OECD countries, their most direct competitors, which will make the journey particularly challenging, as the initial departure-point differences will provide an additional hurdle to overcome.

The article is structured in the following way: Section two reviews the existing literature; Section three presents the propositions to be validated; Section four, discusses the methodology; Section five analyzes the empirical findings and discusses the results; Section six, goes through the managerial implications of the research; Section seven draws the final conclusions.

\section{Literature review}

\subsection{I4.0, a new productivity frontier}

I4.0 can be defined as physical and engineering systems whose operations are integrated, monitored and controlled by a computation and communication core (Monostori et al., 2016). It is, at its core, a combination of technologies (robotics, artificial intelligence, big data, 3D printing as well as the internet of things), that generates a new paradigm in manufacturing (Lasi, Fettke, Feld \& Hofmann, 2014) and creates new business opportunities (Bughin et al., 2016). This new manufacturing paradigm holds a huge potential, with significant social and economic opportunities through work organization, business models and production technology (Kagermann et al., 2013). 
To better understand the nature of its impact, the literature has been reviewed from two different perspectives: First, looking back into history and exploring the development of technologies that have generated significant improvements in productivity, the alternating current motor and information and communication technologies (ICT), where the findings point to the fact that the source of those improvements was, to a significant degree, the process innovation they enabled; Second, the limited evidence available on digitization and robotization, will also be explored and it will be shown that the source of productivity improvement is not only business process innovation but, more importantly, business model innovation. All the evidence points to the very same fact: A big dispersion of productivity and profitability, coming from business model and process innovation, only becoming bigger and more sustainable over time, as digitization increases.

Those conclusions, the result of connecting the dots obtained after reviewing a significant amount of literature, it is believed could be extrapolated to I4.0.

\subsection{New technologies and productivity: Historical evidence}

\subsubsection{The alternating current motor}

David and Wright (1999) demonstrate that, after three decades where productivity grew at an annual rate below one percent, between 1919 and 1929 it did so at more than five. For the authors, this high rate is the precursor of a long period of growth that lasted well into the 1970's and can be attributed not only to critical advances in engineering but also to organizational changes, all linked to electrification. The most important was the widespread use of the unit drive instead of the more traditional group drive, which allowed not only for greater energy efficiency but for the complete reorganization of the plant layout, which brought significant savings in material movement and investment (David \& Wright, 1999).

Nevertheless, electrification did not begin to manifest its impact on productivity until the early 1920's, four decades after the first generating plant was put into operation in 1881 (David, 1990). This delay was related to the low penetration rate of electrification due to the high investment in equipment and plant needed. Consequently, it was in industries that experienced the biggest growth and development at that time (tobacco, metal transformation, transportation) that drove electrification and defined the productivity frontier (David, 1990). For David (op. cit.) and David and Wright (1999), all this has clear parallels with the implementation of information and communication technologies, in the following sense:

- The exceptional magnitude of the productivity increases.

- The deferred impact over time, that should help to manage expectations about the speed of productivity improvement. It is not as much a question of the impact not being profound but that it may take time to show up in the aggregate productivity metrics (David 1990).

- The fact that organizational improvements were the determinants of the transformative impact (David \& Wright, 1999) should shed light on the importance of the non-technological elements.

It is believed here that those similarities can also be extended to I4.0.

\subsubsection{Information and Communication Technologies (ICT)}

Brynjolfsson and Hitt (2003) find a strong correlation between ICT, investment and productivity, this having added annual rates between $0.25 \%$ and $0.5 \%$, with its impact increasing over time. They conclude that ICT make a substantial contribution to the increase of long-term productivity and corroborate existing institutional evidence that this increase is the result of a combination of investment in hardware as well as in organization and business processes. In this sense, work carried out by Brynjolfsson and Yang (1997), suggests that the ratio between intangibles and assets, normally of ten-to-one, can be even higher in cases like enterprise resource planning (ERP), where it represents only about 4\% of the total cost. Emphasizing the importance of the intangible elements, Brynjolfsson and Hitt (2003), show that complementarities are the most plausible reason to explain the relationship between ICT, organizational factors and economic performance. Multiple evidence 
suggests that hidden assets, such as decentralization, organizational practices and people, play a very important role in the relationship between ICT and productivity and are found to be the key elements in firms that achieve higher levels of productivity (Bresnahan, Brynjolfsson \& Hitt, 2002).

Although technology offers the promise of improved performance, to make it happen, it is necessary to adapt organization and people management practices (García-Olaverri, Huerta-Arribas \& Larraza-Kintana, 2007). As the report "Industry 4.0: building the digital enterprise" report (PWC, 2016) concludes, the principle challenge is not so much technology but rather people.

\subsection{Productivity dispersion}

There are significant differences in productivity between countries, this being a very important issue as there is a strong correlation between productivity and GDP per capita (Jones \& Romer, 2010): Productivity is linked to wealth and, ultimately, with the success of countries and businesses. As early as 1957, Solow (1957) found that a very significant part of the growth in labor productivity in the United States was due to productivity growth rather than the accumulation of capital. Syverson (2004) also demonstrates that a plant in the 90th percentile of the productivity distribution of labor is four times more productive than one in the 10th percentile. Baily, Hulten and Campbell (1992), in an analysis of US manufacturing plants, concluded that over a five-year period, almost $50 \%$ of the productivity improvements came from volume relocation between plants.

Andrews, Criscuolo and Gal (2015) state that companies that are in what they call the "global productivity frontier" (the 100 most productive companies in a given 2-digit economic sector) are, on average, four to five times more productive than the rest. These companies have increased labor productivity in the first fifteen years of the 21 st century at an annual rate of $3.5 \%$, compared to $0.5 \%$ for the rest and, in addition, they have higher levels of sales and profitability. For the authors, this suggests that the capacity of companies to learn from those on the frontier has diminished. The findings of the World Economic Forum (2018) are also along the same lines: The overall increase in labor productivity in their 16,000-strong sample was driven by the most productive $20 \%$ of the companies in each industry. Industry leaders delivered a $12 \%$ productivity CAGR while the others only managed $2 \%$, a significant gap by any measure. At firm level, industry leaders - who tend to be larger companies by revenue in most industries - realized greater productivity improvements than the rest (World Economic Forum, 2018). Those differences tend not only to be significant but persistent. Bartelsman and Dhrymes (1998), show that, during a five-year period, approximately a third of the plants surveyed remained in their productivity quintile and Bloom, Lemos, Sadun, Scur and Van Reenen (2014), state that there is ample evidence for the persistence of important productivity differences between companies.

\subsection{I4.0 and productivity: Economic evidence}

Little scientific evidence for the specific productivity impact of I4.0 has been found and what is available is mainly focused on robotization. Graetz and Michaels (2015), analyzing a range of industries in seventeen countries over the period 1993-2007, show that the use of robots increased productivity between 0.36 and $0.37 \%$ per year. It is also worth emphasizing that this value is at the same level as other technologies like the steam boiler (between 1850 and 1910), with an annual growth of $0.35 \%$ (Crafts, 2004). It is interesting to compare this value with that of the implementation of information and communication technologies (ICT), which have generated an annual productivity growth of $0.6 \%$ in Europe, the USA and Japan, between 1995 and 2005 (O'Mahony \& Timmer, 2009). Taking into account that the largest investments in robotization have taken place since 2015, it seems reasonable to expect that its impact will only increase in the coming years (Graetz \& Michaels, 2015).

The CEBR report (2017) deals with the impact of robotization in twenty-three OECD countries, concluding that each percentage point of investment in robots has an impact of $0.05 \%$ on GDP per capita. This value is in line with that obtained by Graetz and Michaels (2015), where each percentage point of increase in investment in robots generates $0.04 \%$ increase in labor productivity. As an indication of what the future may hold, the study concludes that until 2015, the largest increases in robot sales occurred in the automotive industry. However, as 
of today and although the automobile sector has reduced its robot investment, their aggregate sales continued to grow, which suggests a wider use and potentially greater impact as robotization permeates more fields of activity (CEBER report, 2017).

\subsection{Digitization and economic performance}

Brynjolfsson and McAfee (2008) show that the Internet and corporate IT have been accelerating competition within traditional sectors of the US economy. The authors analyzed concentration (measured as percentage of market share held by the largest companies), turbulence (measured as change of leading positions between companies) and profitability spread, (measuring as difference in ROA, profit margins (EBIT) and market capitalization per dollar of income). They have found those variables to have accelerated its growth since the mid-90s, in line with the increase in IT investment, and have accentuated the differences between firms instead of reducing them, especially in the most ICT-intensive sectors. Although companies have always differed in their ability to select, adopt and exploit innovations, technology has only accelerated and amplified these differences (Brynfolfsson \& McAfee, 2008).

Similar conclusions about profitability dispersion can be derived from Deloitte's Shift Index (Deloitte, 2016), where the spread of the return on assets (ROA) between companies in the first and fourth quartiles, has been consistently increasing over the period 1965 - 2015. Even if for those in the first quartile, profitability has fallen from $12.7 \%$ to $8.3 \%$, for those in the fourth, it has gone down from $1.2 \%$ to $-34.8 \%$ over the same period. Reinforcing this conclusion, Autor, Dorn, Katz, Patterson and Van Reenen (2017), in an analysis of the importance of labor in the value added of businesses, show that there is a clear trend towards an increase in sales concentration, in all sectors of the economy, and not only in the United States but also in Europe and in other OECD countries. They also found a positive and very significant correlation between productivity growth and concentration. For them, this correlation suggests that industries that concentrate the most are those with the fastest technological progress and this coming not from more products being digitized but from more processes being so.

In a research carried out beyond the strictly industrial environment, Bughin and Van Zeebroeck (2017) conclude that increases in digitization negatively impact sales and profits of companies in the lower profitability quartile, while those in the upper quartile are bound to capture a disproportionate share of them. According to their analysis, digitization has already reduced, on average, 6 percentage points of annual sales growth and 4.5 percentage points of EBIT of incumbent companies, its pressure is only set to increase over time. The more digitally advanced a sector of economic activity is, the greater the negative impact on traditional companies that do not react (Bughin and Van Zeebroeck, 2017). It is believed here that this can be directly extrapolated to I4.0. In a similar line, Bughin, LaBerge and Mellbye (2017), in their analysis of the use of artificial intelligence, show that companies that have first adopted artificial intelligence are in sectors that are already investing at scale in related technologies such as "cloud computing" and "big data". This is an important conclusion, as it suggests that it is difficult for companies to catch up with the leaders in digitization, as each new generation of technology being built on the back of the previous one (Bughin et al., 2017).

All this points to the fact that, with the increase in digitization brought about by digitization and I4.0, differences in economic performance are set to grow over time.

\subsection{High-performance people management practices, drivers of productivity and innovation}

The literature refers to the group practices that lead to high levels of productivity and economic performance with different terms but the term "high performance" (Huselid, 1995; Posthuma, Campion, Masimova \& Campion, 2013) is believed to be the most suitable one. 


\begin{tabular}{|c|c|}
\hline Practice & Description and key elements \\
\hline Staffing & $\begin{array}{l}\text { A wide variety of means are used to select only the best candidates for a given position. A search } \\
\text { process is not closed until that goal is achieved: } \\
\text { - Use of multiple perspectives, beyond the technical competence: attitude, personality, cultural fit, } \\
\text { interpersonal skills, learning ability. } \\
\text { - Conducting structured interviews. } \\
\text { - Submission to specific tests. }\end{array}$ \\
\hline Training & broad, structured and on-going set of development opportunities for all employees is provided. \\
\hline d & $\begin{array}{l}\text { There are formal mechanisms, structured and programmed, for evaluating the performance of } \\
\text { employees at least once a year and whose results are important for the future development of employees } \\
\text { in the company. } \\
\text { - Promotion based upon performance. } \\
\text { - Proactive management of employees with the worst performance levels. }\end{array}$ \\
\hline & $\begin{array}{l}\text { The company provides an adequate level of compensation, with a part of it being linked to } \\
\text { performance, not only individual but also collective. }\end{array}$ \\
\hline ions & There are channels, means and metrics for managing the relationship with employees in a structured way \\
\hline Comunication & $\begin{array}{l}\text { There are defined communication channels for the exchange of information in both directions. The } \\
\text { employees' opinions are requested and incorporated into the decision-making process and the company } \\
\text { is providing economic, strategy and context information. }\end{array}$ \\
\hline Job c & $\begin{array}{l}\text { A certain level of autonomy in the workplace is provided, so as to facilitate the development of the } \\
\text { employees: } \\
\text { - Empowerment. } \\
\text { - Job rotation. } \\
\text { - Job security. } \\
\text { - Work teams, where members are allowed to distribute the workload themselves. } \\
\text { - Group solving teams. } \\
\text { - Opearly defined objectives and periodic review of their achievement. }\end{array}$ \\
\hline
\end{tabular}

Table 1. Summary of people management practices(Based upon the analysis of: Delery \& Shaw, 2001, 174; De Menezes, Gelade \& Wood, 2008, 469; Huselid, 1995, 646; Urtasun-Alonso, Larraza-Kintana, García-Olaverri \& Huerta-Arribas, 2011, 308; Kehoe \& Wright, 2013, 387; MacDuffie, 1995, 207; Bloom \& Van Reenen, 2010, 206; Chung-Jen Chen \& Jing-Wen Huang, 2009; Jiménez-Jiménez \& Sanz-Valle, 2007, 376; Posthuma et al., 2013; 1192)

A summary of those practices has been compiled in Table 1 and whenever the terms "high performance people management practices" or "people management practices" are used in this paper, it refers to them.

\subsubsection{People management practices and firm performance}

The link between performance and management practices was established as early as 1995. Huselid (1995), on the basis of a large sample of publicly traded companies, found a significant link between a company's human resource practices, its return on assets (ROA) and Tobin's Q. This suggested significant financial payoffs for those willing to implement high-performance work practices. McDuffie (1995) found that automobile assembly plants combining team-based production systems with "high-commitment" HR systems, low inventory and repair buffers, consistently exhibited higher quality and productivity than those using mass-production systems. Becker and Huselid (2006) found that the effect of one standard deviation in the HR system represented a 10$20 \%$ variation in a firm's market value. Combs, Liu, Hall and Ketchen (2006) in a meta-analysis of the relationship between human resource management practices and performance, scanned the existing scientific literature and selected ninety-two studies that examine a total of close to twenty thousand organizations. They concluded that one standard deviation increase in the use of high-performance work practices translates, on average, to a 4.6 percentage-point increase in gross ROA from 5.1 to 9.7. The impact of high-performance work practices on organizational performance is not only statistically significant but managerially important. 
High-performance work practices seem not to be easily replicable by competitors over time. If they were, given the accumulating evidence regarding the relationship between practices and company performance, one would expect that by now such practices would have been adopted by all companies (Delery \& Roumpi, 2017). A system of high-performance practices meet, to some extent, the criteria that contribute to a resource's inimitability, the key to sustainable competitive advantage: social complexity, interconnectedness with other resources (the value of those practices is highly contingent on the other practices, the structure, the human capital, the culture and other resources of the firm), causal ambiguity and path dependency (Delery \& Roumpi, 2017).

\subsubsection{Human resource management practices and innovation}

Laursen and Foss (2003), demonstrate that human resource management practices are also strongly correlated with innovation, especially with the manufacturing companies in their sample. Michie and Sheenan (1999) also reach a similar conclusion. Jiménez-Jiménez and Sanz-Valle (2005) demonstrate that companies that follow an innovation strategy use a set of specific human resource practices. Even if a causal relationship between the two cannot be established, what can be said is that there is a complex relationship, probably with multiple feedback loops. To start with, no company will be able to recruit competent professionals if it does not have a business project where the role that technology and innovation can play is defined (Jiménez-Jiménez \& Sanz-Valle, 2005). Human resource management practices are a necessary ingredient of any successful innovation initiative but not sufficient.

Subramaniam and Youndt (2005) show that the interaction between human and social capital has a positive influence on radical innovation, indicating that the importance of human capital is very closely related to that of social capital. Individual knowledge is not that important unless it is integrated into the company's social network and shared with other members of the organization: Social capital has a positive influence on both radical and incremental innovation. These results reinforce the relevance of relationships (collaborations, networks, partnership, among others) in the innovation capacity of a firm.

According to Collins and Smith (2006), social climate and exchange of knowledge and information explain approximately $76 \%$ of the relationship between management practices and revenue from new products and services, as well as $84 \%$ of the relationship with sales growth. Social capital, however, does not have a direct influence on innovation: It is only indirectly, through its impact on human capital (Cabello-Medina, LópezCabrales \& Valle-Cabrera, 2011), which highlights the special nature of this relationship. Social interaction allows companies to combine knowledge more easily, making the skills and abilities of the team more company-specific and, consequently, more difficult to imitate (Reed, Lubatkin \& Srinivasan, 2006). All the above-mentioned authors agree that the relationship between the different elements of intellectual capital reinforce each other, in a kind of virtuous cycle.

The fact that people management practices have a significant impact on innovation is a very relevant conclusion: Companies do not only have to equip themselves with the right pool of talent, they also have to create the conditions, the environment, for this talent to work together and be able to improve business processes and craft new business models. This is not something that can be taken off the shelf, as the consolidation of those practices requires management attention, perseverance and time.

\subsection{Small and Medium-sized Enterprises (SMEs) and digitization}

While digitization offers new opportunities for SME's, the reality is that a large number of them have not been able to reap the benefits of the technological transition. Existing evidence shows that they are lagging behind in the adoption digital technologies. Across OECD countries, enterprise resource planning (ERP) are popular among large firms (more than 75\% adoption rate in 2014) but less used by SME's (less than 20\%) (OECD, 2017). This adoption lag is mainly due to lack of investment in complementary knowledge-based assets, such as $\mathrm{R} \& \mathrm{D}$, human resources, organizational changes and process innovation, and has implications for their capacity to turn technological change into innovation and productivity growth (OECD, 2017). 
There is evidence that SME's have higher skills deficiencies than large companies and that their training investment is also, on average, significantly weaker (on a per employee basis). They often face challenges in attracting and retaining highly qualified personnel and staff with relevant skills and also have greater difficulties in identifying workers with sought-after skills in the labor market (OECD, 2017). SME's suffer from a low degree of process standardization, less automated production processes and lack of resources, both human and financial to thoroughly address the challenge (Müller, Kiel \& Voigt, 2018).

Even in Germany, a country that has been a pioneer in I4.0 and where there is heavy institutional support, there are concerns about their capacity to see a successful transition. Sommer (2015) states that I4.0 represents a special challenge for them. Even if there is a high level of awareness of the importance, the challenge is very much linked to the size of the company: the smaller the company, the higher the probability of becoming a victim and not a beneficiary of this disruption (Sommer, 2015). This concern is not only coming from their direct impact on the economy and the workforce but also because, failure to adapt may have an impact on big companies, due to their role in the supply chain (Sommer, 2015).

\subsection{The case of Medium-sized Spanish companies}

It has been shown that there is a close relationship between high-performance people management practices, productivity and innovation, with significant differences between countries and firms. But, where do Spain's medium-sized companies stand? A review of the available information shows that they trail behind those of their most direct competing countries in people management practices. As regards innovation and digitization, the information available does not allow us to reach a specific conclusion for medium-sized companies, but as a whole, Spanish companies do not score well, either on innovation or on digitization.

\subsubsection{Spanish companies, people management practices, productivity and innovation}

Chart 1. shows the cumulative growth of total factor productivity between 1984 and 2014, indexed to that of the United States. As can be seen, over those thirty years, there have been important variations and Spain is at the bottom of this set of advanced economies. In a similar vein, O'Mahony and Timmer (2009), in an analysis of the member states of the European Union, the USA and Japan over the ten-year period between 1995 and 2005, show that Europe trails behind the United States and, that Spain is also in bottom spot, even seeing a negative evolution.

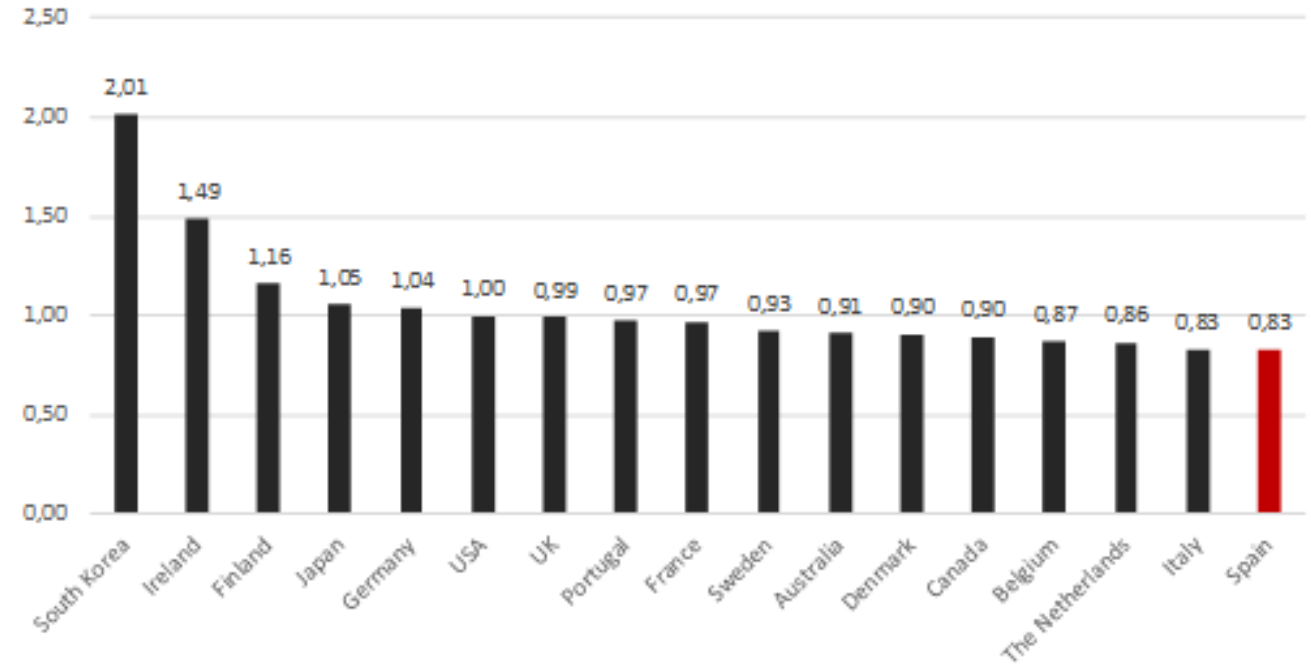

Figure 1. TFP accumulated productivity growth (1984 - 2014); The United States is base 1

(Based upon OCDE data https://stats.oecd.org/Index.aspx?DataSetCode=MFP) 
Those previous indicators are at macroeconomic level and do not specifically point to either industrial firms or medium-sized companies. Bloom and Van Reenen (2010) and Bloom, Sadun and Van Reenen (2016) show that the aggregate management practices, people management practices between them, the score of medium-sized Spanish firms is 2,748 , below those of competing countries such as Italy $(2,978)$, France $(3,015)$ and even Portugal $(2,826)$ and well below that of many OECD countries, which are above the 3,000 level.

Beyond the average, the dispersion is also high, which implies uneven levels of implementation of management practices and, consequently, of productivity (Bloom et al., 2016). If I4.0 can trigger large productivity improvements, redefining even the frontier, then a significant starting deficit can represent a major obstacle.

In what regards to innovation, Moreno and Suriñach (2014), in their analysis of the adoption of innovation and the increase of productivity in Europe between 2000-2005, conclude that Spain, in terms of changes in the adoption of process innovation and productivity growth, has performed quite badly, losing ground in fact in those two variables, something that only happened in Bulgaria, Estonia, Latvia and Hungary. Even if this an analysis done at the aggregate level and not specific to medium-sized companies, size is an important factor in those analyses and the general situation typically deteriorates as size is reduced.

\subsubsection{Spanish companies and digitization}

Similar to what has been presented for productivity and management practices, there is also a large dispersion in the level of adoption of information and communication technologies (ICT), this being relevant because I4.0 make intensive use of them. The "Networked Readiness Index" (World Economic Forum, 2016) places Spain in 35th position (out of 139) behind countries such as France and Portugal, although ahead of Italy in this case.

O'Mahony and Timmer (2009), in their comparative analysis of the productivity of a set of European countries, the United States and Japan in the period 1995-2005, also show that the contribution to labor productivity of the "knowledge economy" (according to them, the sum of the composition of the workforce, the investment in information and communication technologies as well as the TFP) is one of the causes of the significant difference in labor productivity between Europe and the United States. Within Europe, Spain is at the queue, only in front of Italy.

Sirkin, Zinser and Rose (2015), in a comparative analysis of 25 countries that represent $90 \%$ of world trade, conclude that, in countries with a higher rate of adoption of robots, labor costs can become, by 2025, 33\% lower, adjusted to the productivity base increase. On the other hand, countries where the implementation rate is low and have also a combination of high wages, low productivity and labor market restrictions (as is the case in Spain), this improvement would be reduced to between $6 \%$ and $9 \%$.

The IMD World Competitiveness Ranking (2018) shows that, at country level, there is a strong correlation between productivity and digitization. Of the various factors covered by the research, there is one that is especially interesting for this paper: "Future readiness". This factor assesses a country's ability to adopt and explore digital technology and reflects the preparedness of an economy, both at public, private and social levels, to manage the implicit disruptions of digital technologies. The research shows that there is a strong relationship between labor productivity and the level of preparation for the future: A higher level of labor productivity is associated with higher preparation. Spain is in 32nd place, down from twenty-ninth in 2014, the year of the first analysis. Similar to what has been seen in other rankings and something that seems to be a constant, Spain is a little behind Italy and just ahead of Portugal.

\section{Propositions}

The main objective of this research is to prove that high-performance people management practices should be a priority for SMEs in the I4.0 context, this being proposition \#1. 


\begin{tabular}{|c|c|}
\hline Proposition \# & Description \\
\hline 1 & $\begin{array}{l}\text { The consolidation of high-performance people management practices should by a high- } \\
\text { priority task in I4.0. }\end{array}$ \\
\hline 2 & $\begin{array}{l}\text { Firms, in general, are not very aware of the strong correlation between high- } \\
\text { performance people management practices and success in I4.0. }\end{array}$ \\
\hline 3 & $\begin{array}{l}\text { Companies, in general, are not aware of the time and effort needed for the } \\
\text { consolidation of high-performance people management practices. }\end{array}$ \\
\hline 4 & $\begin{array}{l}\text { Firms, in general, are not aware of the importance that high-performance people } \\
\text { management practices have on productivity and innovation. }\end{array}$ \\
\hline 5 & $\begin{array}{l}\text { Companies, in general, are not aware of the significant importance that high- } \\
\text { performance people management practices have on capturing and retaining talent. }\end{array}$ \\
\hline 6 & $\begin{array}{l}\text { The sustainability of I4.0, in a similar way to what happens with "Lean Manufacturing" } \\
\text { will require a cultural transformation. }\end{array}$ \\
\hline 7 & $\begin{array}{l}\text { The complexity of I4.0, from the perspective of people management, is similar to that } \\
\text { of "Lean Manufacturing". }\end{array}$ \\
\hline 8 & $\begin{array}{l}\text { Time, as a competitive variable, will acquire even more relevance with I } 4.0 \text { as, due to } \\
\text { digitization, the accumulated impact of learning becomes an even more difficult barrier } \\
\text { to overcome. }\end{array}$ \\
\hline
\end{tabular}

Table 2. Propositions for validation

Nevertheless, the literature review has unearthed several interesting elements around this challenge. One of those is about the similarities between I4.0 and lean, as this would bring a clear benchmark of the challenges companies are going to face. This is covered by propositions \# 6 and 7. Time, as a competitive variable has been found to be a still more relevant in the context and digitization and has been included as proposition \#8. The remaining propositions want to test the level of awareness that companies have of the causality relations between people management practices, productivity and innovation (\#4) as well as capturing and retaining talent (\#5). Proposition \#3 addresses the awareness of the time and effort needed for its consolidation (\#3).

\section{Methodology}

As the propositions presented in Table 2 are both qualitative and prospective, the Delphi method was chosen for their validation. Delphi is a suitable methodology when the issue to be addressed cannot be handled with precise analytical techniques but through a subjective analysis by a group of experts (Linstone \& Turoff, 1975), and is considered the appropriate one to achieve consensus or stability (Murry \& Hammons, 1995). For this purpose, a panel of experts was also put together, its members being drawn from three different groups:

- Academics, linked to Industry 4.0,operations and/or business administration (twenty-one)

- Leaders of Industry 4.0 practices in management consultancies as well as service and equipment providers to the I4.0 (eighteen)

- CEO's or management board members of medium-sized companies working with Industry 4.0 (nine)

The literature does not define an optimal number of panel members, Murry and Hammons (1995) suggest a minimum of ten and a maximum of twenty-five - thirty, while Okoli and Pawloski (2004) set a range between ten and eighteen. Even if it is true that the reliability of the process increases with size, the reality is that there is no significant improvement beyond those limits (Murry \& Hammons, op. cit.), with ten being the minimum acceptable value. For this panel, fifty-two experts were identified and contacted, all of them with extensive experience in the Spanish market. They were sent a link to an online questionnaire together with some contextual information. Out of those fifty-two experts, twenty-seven (52\%) completed the first round of the online questionnaire and twenty-five completed the second and final rounds (48\%), well within the limits set and above the minimum threshold. For the calculations presented in this paper, only the choices of participants that completed the second round have been considered.

Each question had to be graded in a five-point Likert scale, ranging from "completely agree" (five points) to "totally disagree" (one point). The possibility of carrying out a qualitative justification of the selection made was 
also given in the first round. This qualitative information was used to better understand individual choices as well as to identify potential misunderstandings. The questionnaires were processed over January and February 2019.

Even though the results of the first round where already showing a clear confirmatory trend, a second round was launched, where participants were provided, together with information about their original choice, the average for each question.

\section{Empirical findings and discusion}

Table 3 presents a summary of the view of the experts in the two rounds. On an aggregated basis, as can be seen, the Delphi method delivered the expected convergence, as in all propositions, (with the exception of proposition \#2, where the respondents kept exactly the same choice even after being shown the average of the group's first round) there is a reduction in the standard deviation.

In terms of the most important proposition of this paper, proposition \#1, "the consolidation of highperformance people management practices should be a high-priority task in I4.0", 96\% of the participants agreed (60\% "completely"). This is the answer with the highest mean and a low standard deviation, meaning that there is broad agreement with it and a clear reminder of the key enabler role to be played by those practices.

If awareness is the first step to successfully address any issue, $84 \%$ of the experts agree ( $32 \%$ completely) with proposition \#2, that "firms, in general, are not very aware of the strong correlation between high-performance people management practices and success in I4.0". The fact there is broad agreement with this proposition is, nevertheless, a bit troubling, actions may not be taken due to not knowing that this is an issue. Digging deeper into the details of this lack of awareness, $88 \%$ of the experts agree $(28 \%$ completely) that companies are not aware of the importance of the impact that high-performance people management practices have on productivity (question \#4). That lever will then be hidden to many firms for some time, preventing them from achieving the desired objectives. It is also important that companies are also not aware of the importance that those practices have on capturing and retaining talent (question \#5), where $96 \%$ agree ( $72 \%$ completely). We should not forget that retaining, attracting and getting the most out talent is a challenge in I4.0 (Bhens, Lau \& Sarrazin, 2016; CapGemini, 2017; Kane, Palmer, Phillips, Kiron \& Buckley, 2016). Not to be forgotten and to make things more complex, experts also agree with proposition \#3, that companies are not aware of the time needed to consolidate those practices.

When asked whether firms are also aware of the time and effort needed for the consolidation of highperformance people management practices, $92 \%$ of the participants agree $(32 \%$ completely) that most are not. Compounding the importance of the time perspective, proposition \#8 adds yet another layer of difficulty: 100\% of the participants agree that in I4.0 time can be an even more difficult competitive barrier to overcome. This conclusion is in line with what has been found in the literature (Andrews et al., 2015; Deloitte, 2016; Brynjolfsson \& McAfee, 2008; Bughin \& Van Zeebroeck, 2017) and implies that the gap between leaders and followers may grow over time, in a kind of virtuous cycle for the top performers but a vicious circle for the bottom ones.

The authors also wanted to check (in an exploratory way, this not being in the scope of this paper) whether some links could be established with Lean Manufacturing and I4.0, specifically in terms of implementation complexity. This relationship seems to be little explored and, it was thought, it could provide an interesting insight into the complexity of I4.0. The authors are of the opinion that there are strong similarities between the two, with technology being an added layer of difficulty but that any successful I4.0 implementation would essentially require a conversion similar to that of Lean. Being Lean: a continuous and systematic processes improvement effort to eliminate waste (Liker \& Meier, 2006), it was believed that it was in this process-improvement focus that strong similarities could be found. In fact, many companies feel the pressure to obtain results in the short term and resort to Lean as a tool for achieving it, failing in their attempt (De Menezes et al., 2008; Liker \& Meier, 2006) and the same could be true for I4.0. In fact, the use of a set of Lean tools and concepts, without an adequate management framework, does not generate sustainable improvements over time (De Menezes et al., 2008). The Lean philosophy needs to be consolidated before reaping the benefits and the real challenge is to 
have it permeate the organization, something that requires leadership, time and perseverance of purpose (Liker \& Meier, 2006). With this in mind, if similarities could be drawn between the two, it could be concluded that the execution challenges of I4.0 would be very significant.

In a measure of the strong demands that I4.0 places on firms, $96 \%$ of the experts agree that, similarly to what happens in Lean Manufacturing, I4.0 will require a true "cultural revolution" (question \#6). Nevertheless, when asked whether, from a people management perspective, the complexity was going to be similar to that of "Lean Manufacturing" (question \#7), experts did not agree: Its nature will be different to that of Lean. When justifying their choices and in an anticipation of the challenges I4.0 may entail, most of the respondents seemed to agree that the complexity of I4.0 will be even higher, essentially due to technological issues as well as the fact that I4.0 is perceived to be more "disruptive", while Lean is essentially change in a flexible process specialization dynamic. In any case, it seems that the relationship between I4.0 and Lean could be an area of future research.

Taken altogether, the combination of a lack of awareness, the challenges associated with I4.0, that would appear to be even higher than those of Lean, the time needed for consolidation as well as the kind of growing gap between leaders and followers (not to mention economic resources), could make I4.0 a very significant challenge for medium-sized Spanish companies and probably for many SME's around the world(?).

\begin{tabular}{|c|c|c|c|c|c|}
\hline \multicolumn{2}{|r|}{ Proposition } & \multicolumn{2}{|c|}{ First round } & \multicolumn{2}{|c|}{ Second round } \\
\hline$\#$ & Description & Mean & $\begin{array}{c}\text { Standard } \\
\text { Derivation }\end{array}$ & Mean & $\begin{array}{l}\text { Standard } \\
\text { Derivation }\end{array}$ \\
\hline 1 & $\begin{array}{l}\text { The consolidation of high-performance people } \\
\text { management practices should by a high-priority }\end{array}$ & 4.40 & 0.80 & 4.56 & 0.57 \\
\hline 2 & $\begin{array}{l}\text { Firms, in general, are not very aware of the strong } \\
\text { correlation between high-performance people } \\
\text { management practices and success in I4.0. }\end{array}$ & 4.12 & 0.77 & 4.12 & 0.77 \\
\hline 3 & $\begin{array}{l}\text { Firms, in general, are not aware of the time and effort } \\
\text { needed for the consolidation of high-performance } \\
\text { people management practices. }\end{array}$ & 4.08 & 0.93 & 4.24 & 0.59 \\
\hline 4 & $\begin{array}{l}\text { Firms, in general, are not aware of the importance that } \\
\text { high-performance people management practices have in } \\
\text { productivity and innovation. }\end{array}$ & 3.92 & 0.74 & 4.16 & 0.61 \\
\hline 5 & $\begin{array}{l}\text { Firms, in general, are not aware of the significant } \\
\text { importance that high-performance people management } \\
\text { practices have in capturing and retaining talent }\end{array}$ & 3.92 & 0.69 & 4.16 & 0.61 \\
\hline 6 & $\begin{array}{l}\text { The sustainability of I4.0, in a similar way to what } \\
\text { happens with "Lean Manufacturing" will require a } \\
\text { cultural transformation }\end{array}$ & 4.52 & 0.70 & 4.48 & 0.57 \\
\hline 7 & $\begin{array}{l}\text { The complexity of I4.0, from the perspective of people } \\
\text { management, is similar to that of "Lean Manufacturing" }\end{array}$ & 2.72 & 1.08 & 2.88 & 1.03 \\
\hline 8 & $\begin{array}{l}\text { Time, as a competitive variable, will acquire even more } \\
\text { relevance with I } 4.0 \text { as, due to digitization, the } \\
\text { accumulated impact of learning becomes a barrier even } \\
\text { more difficult to overcome. }\end{array}$ & 4.04 & 0.82 & 4.24 & 0.43 \\
\hline
\end{tabular}

Table 3. Results summary

\section{Managerial implications}

How can SMEs benefit from the findings of this research? Is it possible to provide some recommendations beyond giving a top-priority to the consolidation of high-performance people management practices? This section wants to blend the findings of this research with years of senior management experience, both in big companies and SMEs of one of the authors. It is believed here that this mix of research and hands-on experience can bring some value to this reflection about managerial implications.

When thinking about the response to digitization or automation, there is a tendency to respond head-on, that is, in technology terms, placing robots, automating functions or buying new software. The underlying belief is that 
"it is all about technology". Nevertheless, what the research shows is that, even if there is a significant amount of technology, I4.0 is fundamentally about business process, business model innovation and, at the end, people. For managerial purposes, the findings of this research could be translated as follows:

- Strategy, first. Even if this paper has not dealt with the strategic implications of I4.0, its relevance cannot be underestimated. Most SMEs are already fully loaded with short-term work and it is not easy for management to set aside time to think about the future and to articulate a formal business strategy that encompasses I4.0. If this is already an issue for current business issues, it is even more so for farreaching matters like digitization. Industry 4.0 has to be framed into the context of competitive strategy and SMEs have to think, in broader terms, about the opportunities (and threats) brought about by it.

- It is not (only) about bringing in the right people. Once strategic issues have properly been dealt with or, better yet, at the same time than those are being addressed, serious consideration has to be given to people and people management practices. As it has been said in the previous paragraph, daily work absorbs most of SMEs management time, leaving little for formal considerations like people management practices. Most SMEs are simply not aware of the strong correlation between highperformance people management practices, productivity and innovation. In the same way that the tendency to bring in "technology" was mentioned before, there can also be an inclination to resort to "off-the-shelf" solutions, that is, to recruit people with the missing skills to "fill the gaps", without much consideration about the organizational context. Nevertheless, it precisely this environment that it is key not only for attracting the required talent, but to retain the existing, to develop it internally and, more important, to reap the fruits of all investments made. At the end, innovation is a social process and it is precisely here that people management practices are of great help in building the scaffolding in which I4.0 can develop.

- Think about systems of practices. The temptation to cherry-pick, that is, to select some practices and leave others, can be strong. It may be though, for instance, that providing a certain degree of autonomy at the work place is beyond consideration, even if some others, like variable pay, are addressed. This research shows that this would be a mistake, as systems of practices, if properly managed, reinforce each other. Nevertheless, following the example above, it would probably not be wise to give right away a wide degree of autonomy to a group of people that are neither prepared for it nor have enough context information to properly manage this autonomy. The deployment or development of those practices should be based on a carefully drafted road map, taking into consideration the current company situation.

- Time is ever more important. One of the outcomes of the research is that, time as a competitive variable, it is still more important in I4.0 than it has ever been. It is easy to fall into the temptation of postponing long-term thinking until there is time available which, by the nature of the SMEs business, there will never be. Engaging external help in order to properly address those issues should at least be considered as an option. Not doing so may be due to lack of economic resources but, in many instances, it is the belief that the intricate knowledge that management has about the business will never be matched by outsiders and, consequently, they can bring little value. Nevertheless, the value of the outsiders resides in their ability to ask the right questions, bring in examples from other businesses and set up a structured thought process. In any case, the temptation to find excuses for postponing those high-level, longer-term considerations should be resisted.

\section{Conclusions}

I4.0 has the potential to transform the business landscape through a dramatic increase in productivity, coming not only from improved efficiency but from new business models. This is so much so, that Industry 4.0 is also referred to as the "Fourth Industrial Revolution", in anticipation of the potential transformation impact. 
Relevant to its disruption potential is the fact that there is already a very significant dispersion in productivity between companies. This anticipated, dramatic increase will be on top of that, making the performance gap even bigger and the risks for laggards potentially unbridgeable.

Digging into some past technologies, like the alternating current motor or information and communication technologies, evidence has been found that both have generated significant improvements in productivity but, more relevant to this case, this was done, to a large degree, through the process and business model innovation that those technologies enabled. The limited evidence available of digitization or robotization is very much in line with that and points to this very same fact: Big dispersion of productivity and profitability, coming from new business models and process innovation inherent to a disruption process. Nevertheless, in this case it seems that the advantage generated by the winners is not only sustainable but may be even growing over time, making it difficult for laggards to catch up.

There is solid evidence in the literature that links human resource practices with productivity, being the root cause of this dispersion. There are also strong links between high-performance people management practices and innovation and the need for process and business model innovation will make the role of people management practices probably even more important than in any other past technological innovation.

The case for Spanish medium-sized firms looks, in general, specially challenging, as they are lagging behind in high-performance people management practices and digitization, compared to most OECD countries. Nevertheless, the conclusions of this research should not be restricted to medium-sized Spanish firms: they can be extended to many, if not most, European SMEs. Even if the case of medium-sized Spanish firms seems to be quite challenging, literature shows that most SMEs also suffer from the same issues, even if with different intensity. SMEs are not taking advantage of the new technologies and their participation in the knowledge-based economy is also held back by skill shortages, poor internal management practices and low levels of workforce training. They have low scores in consolidation of high-performance people management practices and they are lagging behind in the adoption of digital technologies. While digitization offers new opportunities for SME's, the reality is that a large number of them have not been able to reap the benefits of the technological transition. Those departing gaps will make the I4.0 challenge a very relevant one.

Somewhat paradoxically, in this Fourth Industrial Revolution, one that makes an intensive use of digital technologies, people management practices may be even more important than they had been to date. Businesses willing to embark on I4.0 should not be distracted by technology, even if it will play a very important role, and think about consolidating high-performance people management practices (and certainly business strategy) and making that a high-priority task. This would be an additional hurdle for many, as it would come on top of a low productivity base and lower levels of digitization. Rewards promise to be big, but challenges seem to be consequential.

\section{Declaration of Conflicting Interests}

The authors declared no potential conflicts of interest with respect to the research, authorship, and/or publication of this article.

\section{Funding}

The authors received no financial support for the research, authorship, and/or publication of this article.

\section{References}

Andrews, D, Criscuolo, Ch., \& Gal, P. (2015). Frontier firms, technology diffusion and public policy: Micro evidence from OECD countries. Retrieved from: https://www.oecd.org/eco/growth/Frontier-Firms-TechnologyDiffusion-and-Public-Policy-Micro-Evidence-from-OECD-Countries.pdf

Autor, D., Dorn, D, Katz, L.F., Patterson, C., \& Van Reenen, J. (2017). The fall of labor share and the rise of superstar firms. NBER National Bureau of Economic Research. https://doi.org/10.3386/w23396 
Baily, M.N., Hulten, C., \& Campbell, D. (1992). Productivity dynamics in manufacturing plants. Brookings Papers on Economic Activity, 23(1992 Microeconomics), 187-267. https://doi.org/10.2307/2534764

Bartelsman, E.J., \& Dhrymes, P. (1998). Productivity dynamics: U.S. manufacturing plants, 1972-1986. Journal of Productivity Analysis, 9, 5-34. https://doi.org/10.1023/A:1018383629341

Becker, B.E., \& Huselid, M.A. (2006). Strategic Human Resources Management: Where Do We Go From Here? Journal of Management, 32(6), 898-925. https://doi.org/10.1177/0149206306293668

Bhens, S., Lau, L., \& Sarrazin, H. (2016). The new tech talent you need to succeed in digital. Digital McKinsey, septiembre 2016. Retrieved from: https://www.mckinsey.com/business-functions/digital-mckinsey/our-insights/the-new-techtalent-you-need-to-succeed-in-digital

Bloom, N., \& Van Reenen, J. (2010). Human resource management and productivity. Handbook of Labor Economics, 4(part B), 1697-1767. https://doi.org/10.3386/w16019

Bloom, N., Lemos, R., Sadun, R., Scur, D., \& Van Reenen, J. (2014).The new empirical economics of management. Journal of the European Economic Association, 12(4), 835-876. https://doi.org/10.1111/jeea.12094

Bloom, N., Sadun, R., \& Van Reenen, J. (2016). Management as a technology? Harvard Business School, working paper 16-133. https://doi.org/10.3386/w22327

Bresnahan, T.F., Brynjolfsson, E., \& Hitt, L.M. (2002). Information technology, workplace organization and the demand for skilled labor: firm level evidence. The Quarterly Journal of Economics, 117(1), 339-376. https://doi.org/10.1162/003355302753399526

Brynjolfsson, E., \& Hitt, L.M. (2003). Computing productivity: firm-level evidence. Review of Economics and Statistics, 85(4), 793-808. https://doi.org/10.1162/003465303772815736

Brynjolfsson, E., \& Mc Afee, A. (2008). Investing in the IT that makes a competitive difference. Harvard Business Review, 86(7), 98-107.

Brynjolfsson, E., \& Yang, S. (1997). The intangible benefits and costs of computer investments: Evidence from the financial markets. ICIS '97 Proceedings of the Eighteenth International Conference on Information Systems, 147-166.

Bughin, J., Hazan, E., Labaye, E., Manyika, J., Dahlström, P., Ramaswamy, S. et al. (2016). Digital Europe: Pushing the frontier, capturing the benefits. McKinsey Global Institute. Retrieved from: https://www.mckinsey.com/ /media/McKinsey/Business\%20Functions/McKinsey\%20Digital/Our $\% 20$ Insights $/$ Digital $\% 20$ Europe $\% 20$ Pushing $\% 20$ the $\% 20$ frontier $\% 20$ capturing $\% 20$ the $\% 20$ benefits/Digital-EuropeFull-report-June-2016.ashx

Bughin, J., LaBerge, L., \& Mellbye, A. (2017). The case for digital reinvention. McKinsey Quarterly, February 2017. Retrieved from: https://www.mckinsey.com/business-functions/digital-mckinsey/our-insights/the-case-for-digitalreinvention

Bughin, J., \& Van Zeebroeck, N. (2017). The best response to digital disruption. MIT Sloan Management Review, 58(4), 80-86. https://doi.org/10.5465/AMBPP.2017.15155abstract

Cabello-Medina, C., López-Cabrales, A.,\& Valle-Cabrera, R. (2011).Leveraging the innovative performance of human capital through HRM and social capital in Spanish firms. The International Journal of Human Resource Management, 22(4), 807-828. https:// doi.org/10.1080/09585192.2011.555125

CapGemini (2017). The digital talent gap 2017. Retrieved from: https://www.capgemini.com/wpcontent/uploads/2017/10/dti the-digital-talent-gap 20171109.pdf

CEBR, Centre for Economic and Business Research (2017). The Impact of Automation. Retrieved from: https://cebr.com/reports/new-study-shows-u-s-is-world-leader-in-robotics automation/impact of automation report 23012017 final/

Chung-Jen, C., \& Jing-Wen, H. (2009). Strategic human resource practices and innovation performance: The mediating role of knowledge management capacity. Journal of Business Research, 62, 104-114.

https://doi.org/10.1016/j.jbusres.2007.11.016 
Collins, C.J., \& Smith, K.G. (2006). Knowledge exchange and combination: The role of human resource practices in the performance of high-technology firms. Cornell University ILR School. Retrieved from: https://works.bepress.com/christopher collins/30/ https://doi.org/10.5465/amj.2006.21794671

Combs, J., Liu, Y., Hall, A., \& Ketchen, D. (2006). How much does high-performance work practices matter? A meta-analysis of their effects on organizational performance. Personal Psychology, 59, 501-528. https://doi.org/10.1111/j.1744-6570.2006.00045.x

Crafts, N. (2004). Steam as a general-purpose technology: A growth accounting perspective. The Economic Journal, 114(495), 338-351. https://doi.org/10.1111/j.1468-0297.2003.00200.x

David, P.A. (1990). The dynamo and the computer: an historical perspective on the modern productivity paradox. The American Economic Review, 80(2), 355-362.

David, P.A., \& Wright, G. (1999). General-purpose technologies and productivity surges: Historical reflections on the future of the ICT revolution. The economic future in historical perspective. Oxford University, Discussion Papers in Economic and Social History (31).

Delery, J.E., \& Shaw, J.D. (2001). The strategic management of people in work organizations: Review, synthesis and extension. Research in Personnel and Human Resources Management, 20, 165-197. https://doi.org/10.1016/S07427301(01)20003-6

Delery; J.E., \& Roumpi, D. (2017). Strategic human resource management, human capital and competitive advantage: Is the field going in circles?. Human Resource Managament Journal, 27(1), 1-21. https://doi.org/10.1111/1748-8583.12137

Deloitte (2016). Shift index metrics: The burden of the past, 2016. Retrieved from: http://Dupress.com/

De Menezes, L., Gelade, G., \& Wood, S. (2008). The integration of human resource and operation management practices and its link with performance: A longitudinal latent class study. Journal of Operations Management, 28(6), 455-471. https://doi.org/10.1016/j.jom.2010.01.002

Drath, R., \& Horch, A. (2014). Industrie 4.0: Hit or hype?. IEEE Industrial Economics Magazine, 8(2), 56-58. https://doi.org/10.1109/MIE.2014.2312079

García-Olaverri, C., Huerta-Arribas, E., \& Larraza-Kintana, M. (2007). Human and organizational capital: Typologies among Spanish firms. The International Journal of Human Resource Management, 17(2), 316-330. https://doi.org/10.1080/09585190500404788

Graetz, G., \& Michaels, G. (2015). Robots at work. Centre for Economic Performance, London School of Economics, discussion paper 1335.

Huselid, M.A. (1995). The impact of human resource management practices on turnover, productivity and corporate financial performance. Academy of Management Journal, 38(3), 635-872. https://doi.org/10.2307/256741

IMD (2018). World Digital Competitiveness Ranking 2018. Retrieved from: https://www.imd.org/wcc/worldcompetitiveness-center-rankings/world-digital-competitiveness-rankings-2018/

Ibarra, D., Ganzarain, J., \& Igartua, J.I. (2017). Business model innovation through industry 4.0: A review. Procedia Manufacturing, 22(2018), 4-10. https://doi.org/10.1016/j.promfg.2018.03.002

Jiménez-Jiménez, D., \& Sanz-Valle, R. (2005). Innovation and human resource management fit: An empirical study. International Journal of Manpower, 26(4), 364-380. https://doi.org/10.1108/01437720510609555

Jones, C., \& Romer, P.M. (2010). The new Kaldor facts: Ideas, institutions, population and human capital. American Journal of Macroeconomics, 2(1), 224-245. https://doi.org/10.1257/mac.2.1.224

Kagermann, H., Wahslter W., \& Helbig, J. (2013). Securing the future of German manufacturing industry: Recommendations for implementing the strategic initiative Industrie 4.0. Acatech. Retrieved from: https://www.bmbf.de/files/Umsetzungsempfehlungen Industrie4 0.pdf 
Kane, G.C., Palmer, D., Phillips, A.G., Kiron, D., \& Buckley, N. (2016). Aligning the organization for its digital future. MIT Sloan Management Review, Summer 2016. Retrieved from: https://sloanreview.mit.edu/projects/aligning-for-digital-future/

Kehoe, R.R., \& Wright, P.M. (2013). The impact of high-performance human resource practices on employees' attitudes and behaviours. Journal of Management, 39(2), 366-391. https://doi.org/10.1177/0149206310365901

Lasi, H., Fettke, P., Feld, T., \& Hofmann, M. (2014). Industry 4.0. Business \& Information Systems Engineering, 6(4), 239-242. https://doi.org/10.1007/s12599-014-0334-4

Laursen, K., \& Foss, N.J. (2003). New human resource management practices, complementarities and the impact on innovation performance. Cambridge Journal of Economics, 27, 243-263. https://doi.org/10.1093/cje/27.2.243

Liker, J.K., \& Meier, D. (2006). The Toyota way field book: a practical guide for implementing Toyota's 4Ps. New York: McGraw-Hill. ISBN 0-07-144893-4.

Linstone, H.A., \& Turoff, M. (1975). The Delphi method: techniques and applications. Reading, Massachusetts: Addison-Wesley Publishing Company.

McDuffie, J.P. (1995). Human resource bundles and manufacturing performance: Organizational logic and flexible production systems in the world auto industry. Industrial and Labor Relations Review, 48(2), 197-221. https://doi.org/10.1177/001979399504800201

Michie, J., \& Sheenan, M. (1999). HRM practices, R\&D expenditure and innovative investment: Evidence from the UK's 1990 Workplace Industrial Relations Survey. Industrial and Corporate Change, 8, 211-234.

https://doi.org/10.1093/icc/8.2.211

Monostori, L., Kádár, B., Bauernhansl, T., Kondoh, S,.Kumara, S., Reinhart, G. et al. (2016). Cyber physical systems in manufacturing. CIRP Annals, Manufacturing Technology, 65, 621-641.

https://doi.org/10.1016/j.cirp.2016.06.005

Moreno, R., \& Suriñach, J. (2014). Innovation adoption and productivity growth. Research Institute of Applied Economics, working paper 2014/3. Retrieved from: http://www.ub.edu/irea/working papers/2014/201413.pdf

Müller, J.M., Kiel, D., \& Voigt, K-I. (2018). What drives the implementation of Industry 4.0? The role of opportunities and challenges in the context of sustainability. Sustainability, 10(1), 247. https://doi.org/10.3390/su10010247

Murry, J.W. Jr, \& Hammons, J.O. (1995). Delphi: A versatile methodology for conducting qualitative research. The Review of Higher Education, 18(4), 426-436. https://doi.org/10.1353/rhe.1995.0008

OECD (2017). Enhancing the contributions of SMEs in a global and digitalized economy. Retrieved from: https://www.oecd.org/mcm/documents/C-MIN-2017-8-EN.pdf

Okoli, C., \& Pawloski, S.D. (2004). The Delphi Method as a research tool: An example, design considerations and applications. Information \& Management, 42, 15-29. https://doi.org/10.1016/j.im.2003.11.002

O'Mahony, M., \& Timmer, M.P. (2009). Output, input and productivity measures at industry level: The EU KLEMS database. Economic Journal, 119(538), F374-F403. https://doi.org/10.1111/j.1468-0297.2009.02280.x

Pereira, A.C., \& Romero, F. (2017). A review of the meanings and the implications of the industry 4.0 concept. Procedia Manufacturing, 13, 1206-1214. https://doi.org/10.1016/j.promfg.2017.09.032

Posthuma, R.A., Campion, M.C., Masimova, M., \& Campion, M.A. (2013). A high-performance work practices taxonomy: Integrating the literature and directing future research. Journal of Management, 39(5), 1184-1220. https://doi.org/10.1177/0149206313478184

PWC (2016). Industry 4.0: Building the digital enterprise. Retrieved from: https://www.pwc.com/gx/en/industries/industries-4.0/landing-page/industry-4.0-building-your-digital-enterprise-april$\underline{2016 . p d f}$ 
Reed, K.K., Lubatkin, M., \& Srinivasan, N. (2006). Proposing and testing an intellectual capital-based view of the firm. Journal of Management Studies, 43(2), 867-893. https://doi.org/10.1111/j.1467-6486.2006.00614.x

Schuh, G, Potente, T, Wesch-Potente, C, \& Hauptvogel, A. (2013). Sustainable increase of overhead productivity due to cyber-physical systems. Proceedings of the 11th Global Conference on Sustainable Manufacturing - Innovative solutions, 332-335.

Sirkin, H, Zinser, M., \& Rose, J.R. (2015). The robotics revolution: The next great leap in manufacturing. The Boston Consulting Group. Retrieved from: https://www.bcg.com/publications/2015/lean-manufacturing-innovationrobotics-revolution-next-great-leap-manufacturing.aspx

Solow, R.M. (1957). Technical change and the aggregate production function. The Review of Economics and Statistics, 39(3), 312-320. https://doi.org/10.2307/1926047

Sommer, L. (2015). Industrial revolution - Industry 4.0: Are German manufacturing SMEs the first victims of this revolution?. Journal of Industrial Engineering and Management, 8(5), 1512-1532.

https://doi.org/10.3926/jiem.1470

Subramaniam, M., \& Youndt, M.A. (2005). The influence of intellectual capital on the types of innovative capabilities. Academy of Management Journal, 48(3), 450-463. https://doi.org/10.5465/amj.2005.17407911

Syverson, C. (2004). Product substitutability and productivity dispersion. Review ofEconomics and Statistics, 86(2), 534-550. https://doi.org/10.1162/003465304323031094

Urtasun-Alonso, A., Larraza-Kintana, M., García-Olaverri, C., \& Huerta-Arribas, E. (2011). Manufacturing flexibility and advanced human resource practices. Production Planning \& Control, 25(4), 303-317. https://doi.org/10.1080/09537287.2012.690198

World Economic Forum (2016). The global information technology report 2016: Innovating in the digital economy. Insight Report. Retrieved from: http://www3.weforum.org/docs/GITR2016/WEF GITR Full Report.pdf

World Economic Forum (2018). Digital transformation initiative: Maximizing the return on digital investments. Retrieved from: http://www3.weforum.org/docs/DTI Maximizing Return Digital WP.pdf

Article's contents are provided on an Attribution-Non Commercial 4.0 Creative commons International License. Readers are allowed to copy, distribute and communicate article's contents, provided the author's and Intangible Capital's names are included. It must not be used for commercial purposes. To see the complete license contents, please visit https://creativecommons.org/licenses/by-nc/4.0/. 